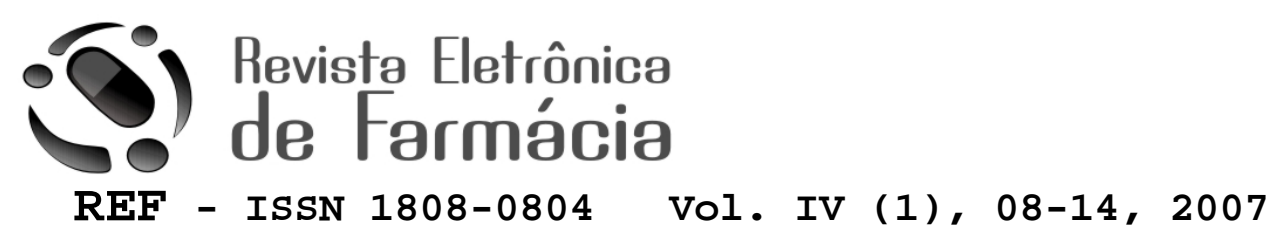

\title{
IMPORTÂNCIA FARMACÊUTICA DE FÁRMACOS QUIRAIS
}

\author{
The pharmaceutical importance of chiral drugs \\ ${ }^{1 *}$ Ricardo Mathias Orlando, Normandis Cardoso Filho, ${ }^{2 *}$ Eric de Souza Gil, ${ }^{3}$ João Paulo \\ de Souza Stringhetta. \\ ${ }^{1 *}$ Prof. da disciplina de Análises Toxicológicas da Universidade para o Desenvolvimento do Estado e da Região do \\ Pantanal, Campo Grande, MS. \\ ${ }^{2 *}$ Prof. da disciplina de Bioquímica da Universidade para o Desenvolvimento do Estado e da Região do Pantanal, \\ Campo Grande, MS \\ ${ }^{1 *}$ Prof. da Controle de Qualidade do Curso de Farmácia da Universidade Federal de Goiás, Goiânia, GO \\ ${ }^{3^{*}}$ Aluno de Iniciação Científica da Universidade para o Desenvolvimento do Estado e da Região do Pantanal, \\ Campo Grande, MS \\ *Autor para correspondência e-mail: orlando@iqm.unicamp.br
}

Recebido em 12/02/2007-Aceito em 25/06/2007

RESUMO: O conhecimento sobre a existência e as diferenças entre enantiômeros data de mais de um século. Mas foi somente com a tragédia da talidomida na década de 60 que o mundo voltou-se para a importância dos estudos e do controle de fármacos enantioméricos. Hoje, no mundo todo, existir uma grande preocupação em obter estudos mais aprofundados sobre as possíveis diferenças entre dois enantiômeros assim como uma forte tendência para a obtenção de patentes, produção, comercialização e utilização de enantiômeros puros em alguns casos. Em contracorrente o Brasil mostra-se alheio ao assunto principalmente do ponto de vista comercial. Neste contexto sua população encontra-se exposta a riscos e desinformações típicas de um período que há muito tempo deveria ter sido superado.

ABSTRACT: The knowledge about the existence and the differences among enantiomers dates of more than one century ago. But only after the thalidomide tragedy in the decade of 60 , the world turned to the importance of the studies and control of enantiomeric drugs. Today, over the word, there is a great concern to get more deep studies about the possible differences between two enantiomers as well as a strong tendency to obtain patents, production, trade and use of pure enantiomers in some cases. Nevertheless, in Brazil this tendency is not observed, mainly by the economic point of view. That situation puts the country on this side in a position of their social, economical and scientific potentialities. In this context the Brazilian population is exposed to risks and typical disinformation of a period that should be outmoded a long time ago.

\section{INTRODUÇÃO}

O início do estudo e da compreensão dos fenômenos quirais e, por conseqüência, da estereoquímica é atribuído, em parte, a Jean-Baptist Biot, Lous Pausteur e van'Hoff/Le Bel que descobriam, durante o século XIX, a capacidade de alguns compostos de desviar a luz plano polarizada, a assimetria molecular desses compostos e a configuração tetraédrica do átomo de carbono, respectivamente (HYNECK et al., 1990). A partir dessas descobertas foi possível compreender que substâncias que não possuem elemento de simetria no arranjo espacial de seus grupos ligantes irão apresentar-se na forma de dois enantiômeros que são imagens especulares entre sí.

Estereoisômeros são divididos em duas categorias. Uma categoria compreende os enantiômeros, nos quais a molécula apresenta a geometria e a disposição espacial de seus átomos igual à imagem especular do seu par complementar, chamado de antípoda óptico. Somente os compostos ditos quirais, ou seja, que não possuem elemento de simetria, apresentam essa característica (SOLOMONS \& FRYHLE 2000, ELIEL \& WILEN, 1994). Na outra categoria estão os chamados diastereoisômeros, cujas moléculas possuem diferentes arranjos espaciais de seus ligantes, porém não são imagens especulares sobreponíveis umas das outras (Figura 1). 


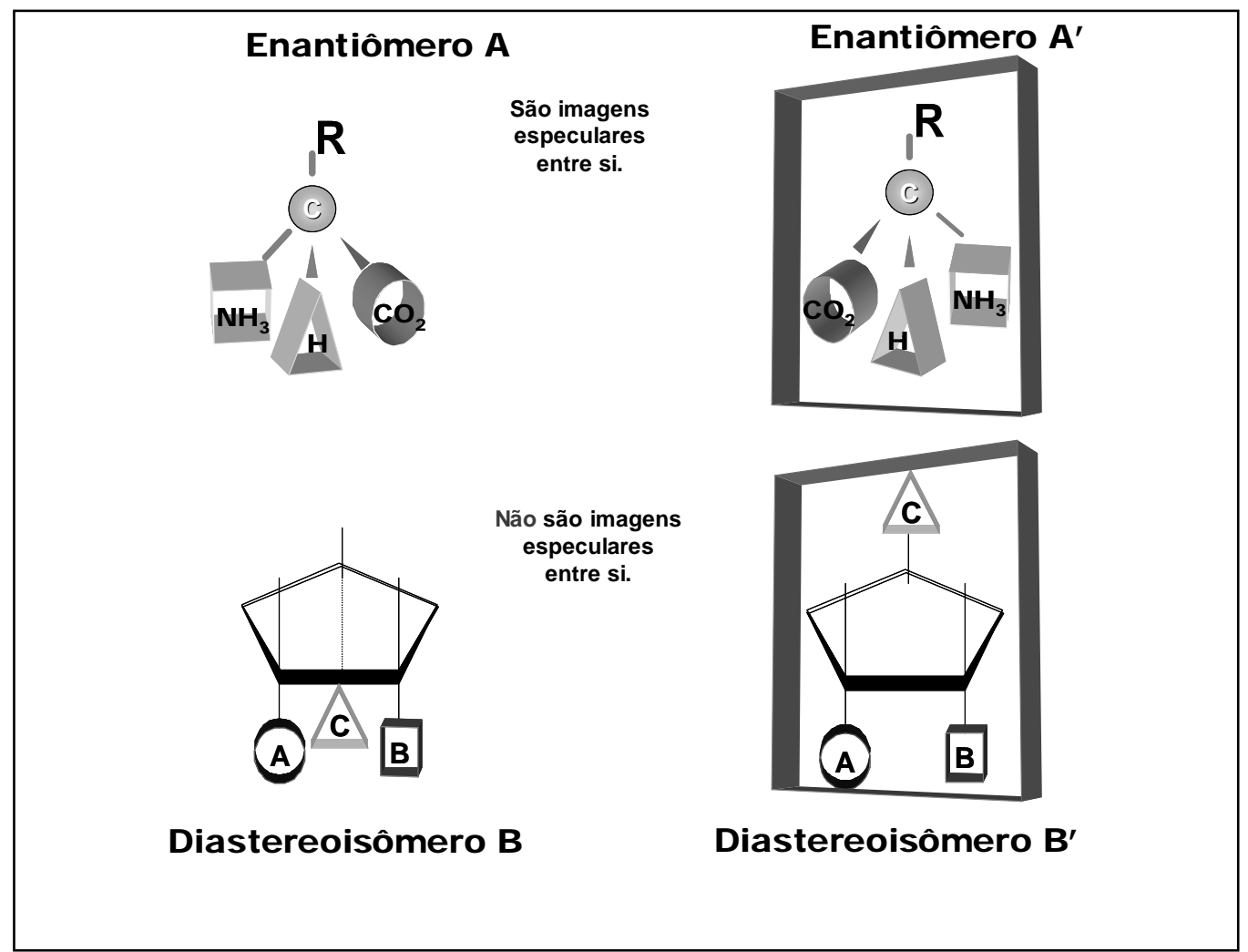

Fig. 1 - Representação de dois enantiômeros e dois diastereoisômeros.

De acordo como o arranjo espacial, os enantiômeros recebem os prefixos $\mathrm{R}$ ou $\mathrm{S}$ seguindo o sistema de nomenclatura desenvolvido pelos químicos R. S. Cahn, C. K. Ingold e V. Prelog em 1966 e adotado pela International Union of Pure and Applied Chemistry (IUPAC).

Existe também uma outra nomenclatura atribuída aos enantiômeros e que esta relacionada à sua capacidade de desviar a luz plano polarizada para a direita $(D$ ou +$)$ e para a esquerda ( $L$ ou -). Esta propriedade que compostos quirais podem apresentar depende não somente do arranjo espacial dos seus átomos, mas também do meio em que eles se encontram. Um exemplo são os enantiômeros do anticoagulante varfarina onde o enantiômero $S$ apresenta rotação positiva (D) e o R rotação negativa (L) em n-hexano-2-propanol (90:10, v/v), enquanto que em n-hepatano-acetato de etila $(80: 20, \mathrm{v} / \mathrm{v})$ o desvio é negativo para o enantiômero $\mathrm{S}$ e positivo para R (FRANCOTTE, 2001). Dessa forma, podemos perceber que as denominações R-S e D-L são independentes e, portanto podemos ter enantiomeros (+)-(S)- ou (-)-(S)- e da mesma maneira o enantiômero (+)(R)- ou (-)-(R)-.

Um outro tipo de compostos quirais e também de grande importância farmacêutica são os chamados atropoisômeros (SANTOS, et al, 2007). Atropoisômeros são compostos quirais que originados pelo impedimento estérico de uma ou mais ligações simples. Por esse motivo atropoisômeros são também conhecidos por rotâmeros. 


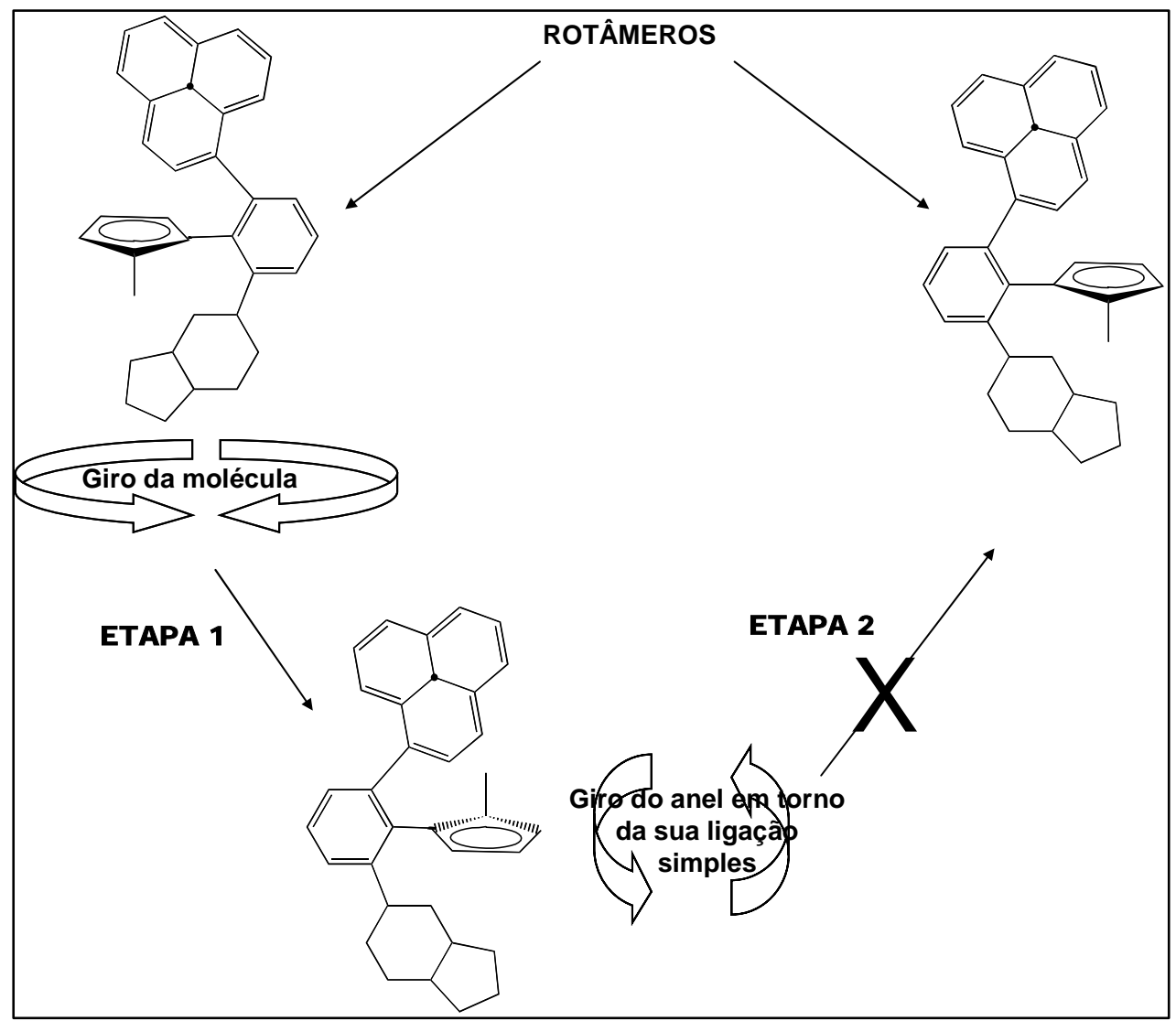

Fig. 2 - Representação de dois rotâmeros (atropoisômeros) hipotéticos e o impedimento de rotação de um dos seus anéis em torno da ligação simples.

\section{ESTEREOQUÍMICA DE FÁRMACOS}

Fármacos enantioméricos recebem maior atenção em estudos farmacológicos, pois as vias sintéticas de fármacos quirais, em sua maioria, não são estereosseletivas levando à formação de ambos os enantiômeros (ROMERO, 1998) e, também, devido às dificuldades técnicas e econômicas em separar os mesmos, o que é possível somente em ambientes quirais. Por esses motivos, fármacos enantioméricos são quase sempre comercializados na forma de misturas racêmicas (MARZO, 1993), ou seja, uma mistura de quantidades iguais dos enantiômeros (SOLOMONS \& FRYHLE, 2000).

Enantiômeros apresentam a maioria de suas propriedades físicas idênticas e, quimicamente, eles demonstram comportamentos diferentes somente em ambientes quirais. Essa característica é de extrema importância biológica uma vez que a maioria dos receptores endógenos de fármacos, como proteínas de membranas e enzimas também são compostos quirais (ROMERO, 1998).

A discriminação estereosseletiva de dois enantiômeros por receptores biológicos deve-se à interação espacialespecífica fármaco-receptor, explicada pela teoria dos três pontos, inspirada por Easson e Stedman e, segundo a qual, somente um dos enantiômeros é capaz de apresentar três pontos de interação complementares, dispostos espacialmente de tal maneira que possam se ligar ao receptor, promovendo o efeito máximo (Figura 3)(SOLOMONS \& FRYHLE, 2000). A teoria dos três pontos também explica as possíveis diferenças de resposta dos receptores de fármacos frente a diastereoisômeros de posição alicíclicos (BARREIRO \& FRAGA, 2001). No caso de isômeros geométricos são necessários quatro pontos de interação para que haja distinção. 


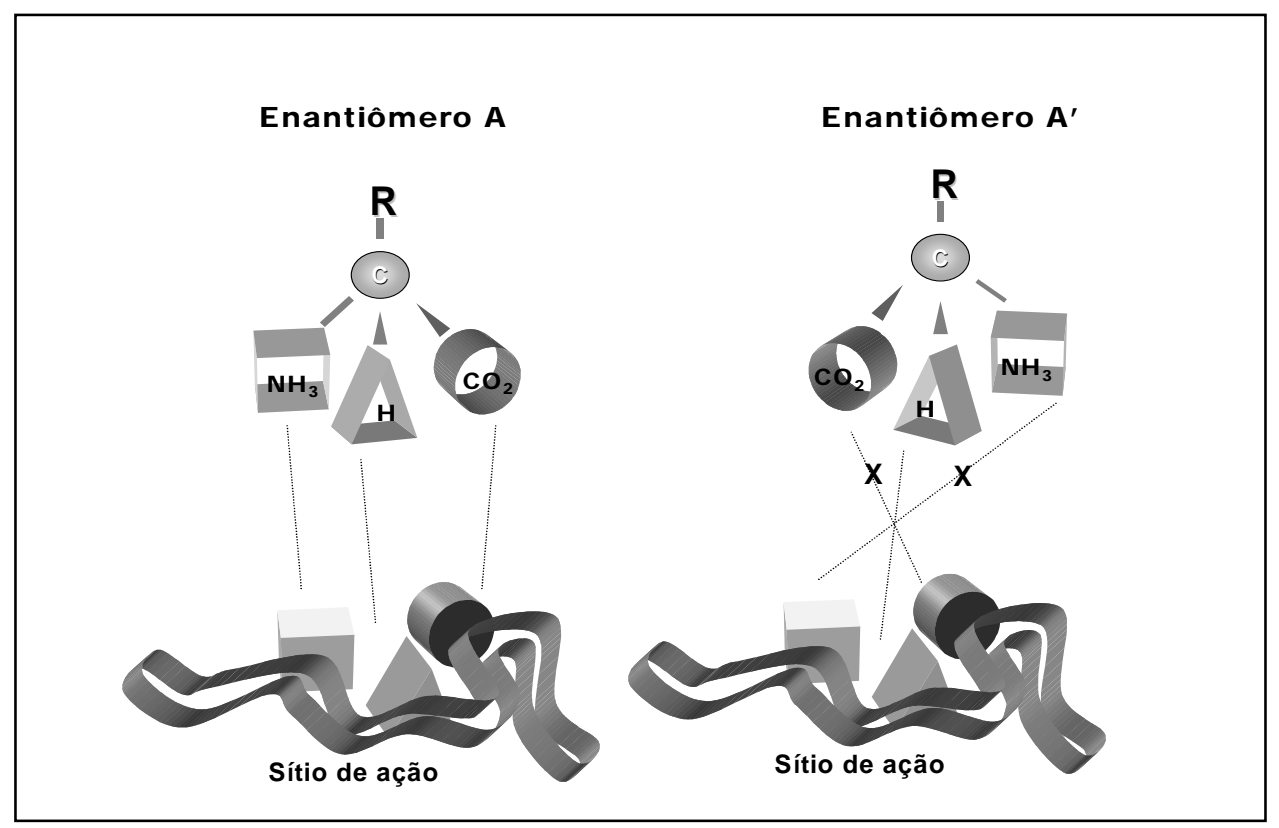

Fig. 3 - Representação da diferença de interação de dois enantiômeros com um receptor quiral devido às suas configurações absolutas

Essas interações altamente específicas fármaco-receptor podem levar também a diferenças farmacocinéticas (Figura 4). Da mesma forma, a absorção, distribuição, eliminação e, principalmente, o metabolismo de estereoisômeros podem ser altamente específicos pois, em muitos casos, são realizados por proteínas com alto grau de discriminação estereosseletiva (HYNECK et al., 1990; Caldwell, 1995).

Depois da tragédia ocorrida com a talidomida, em razão do (-)-(S)- enantiômero apresentar efeitos teratogênicos, levando, por falta de conhecimento das diferenças toxicológicas entre os enantiômeros, à má formação de milhares de fetos, novos modelos de estudos para fármacos quirais foram desenvolvidos (Caldwell, 1995). A partir de então, passou-se a estudar a influência do arranjo espacial dos átomos nas moléculas na interação com macromoléculas biológicas e o quanto isso influenciava os processos bioquímicos, fisiológicos e farmacológicos.

No Brasil, diversos pesquisadores já alertaram sobre a importância do tema (SANTOS et al, 2007; COELHO, 2001; BARREIRO et al, 1997; LIMA, 1997; BERMUDEZ \& BARRAGAT, 1996).

Hoje, sabe-se que muitos fármacos quirais apresentam diferenças estereosseletivas significativas quanto à potência, toxicidade, absorção e metabolismo (Tabela 1). Dessa forma, as agências mundiais regulamentadoras de saúde exigem o estudo dos enantiômeros isolados, incluindo a avaliação de racemização do centro quiral além de preconizar a comercialização de fármacos quirais na forma de enantiômeros puros (SHINDO \& CALDWELL, 1995).

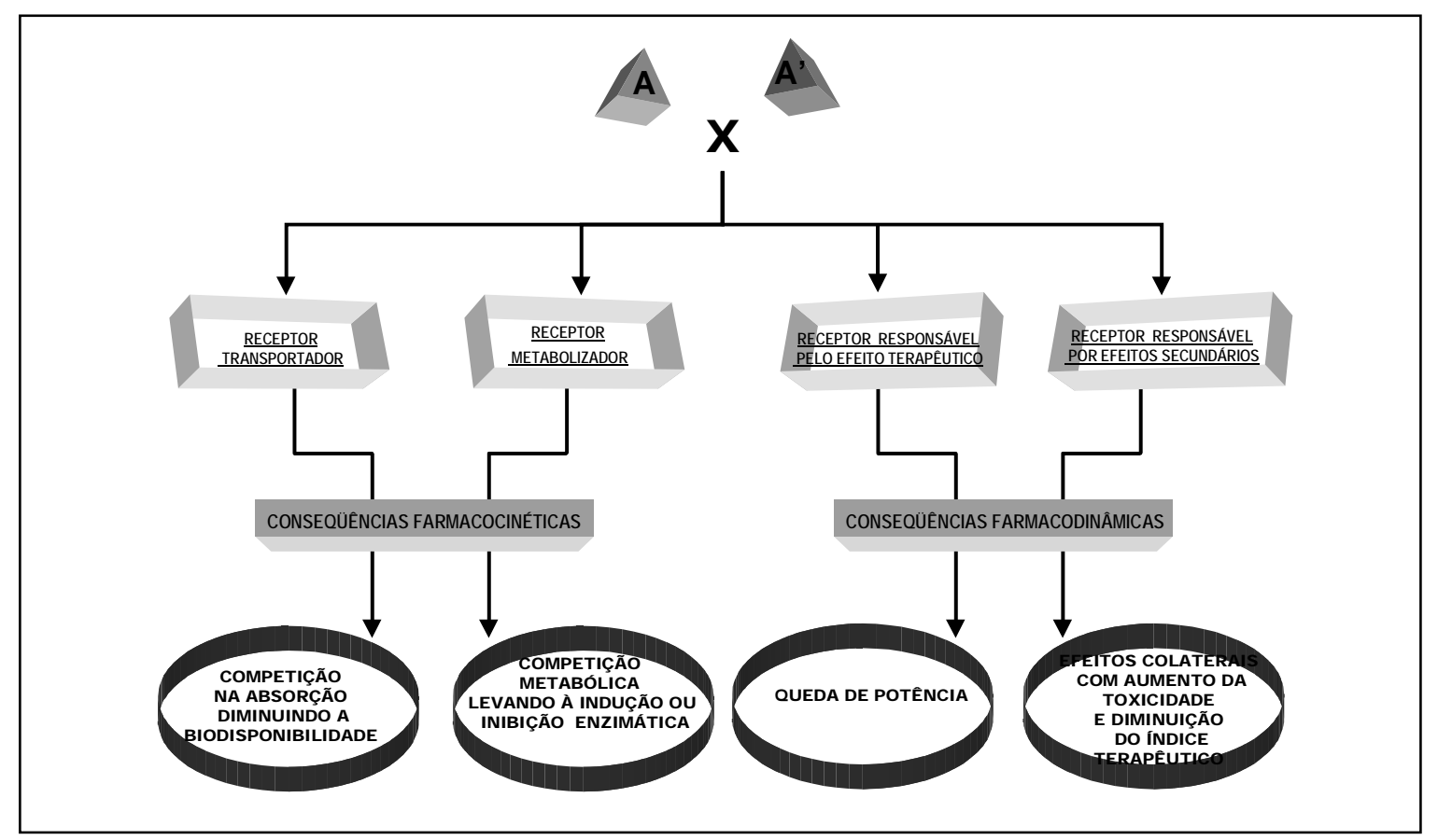

Fig. 4 - Esquema representando as possíveis conseqüências devido às diferenças de afinidade entre 
Tabela 1 - Diferenças farmacocinéticas e farmacodinâmicas de alguns fármacos quirais

\begin{tabular}{cl}
\hline FÁRMACO QUIRAL & \multicolumn{1}{c}{ DIFERENÇAS FARMACOCINÉTICAS E OU FARMACODINÂMICAS } \\
DOS ENANTIÔMEROS
\end{tabular}

Vários países possuem legislação própria quanto ao desenvolvimento e comercialização de fármacos enantioméricos. Nota-se entre elas que muitos pontos são convergentes em relação a importância do assunto e as normas exigidas, principalmente no que diz respeito aos ensaios de bioequivalência (NOËL et al., 2004). No Brasil o controle e legislação vigentes são regulamentados pela Anvisa através da RE n896 e RDC n`135 ambas de 29 de maio de 2003.

No caso em que dois enantiômeros possuem potência de ação diferente a IUPAC recomenda que o enantiômero de maior ação farmacológica e afinidade pelo receptor seja denominado de eutômero enquanto que o outro enantiômero responsável pelo efeito indesejado seja denominado distômero. Além disso, a proporção da atividade do eutômero em relação ao distômero recebe a denominação de razão eudísmica e representa a eficácia ou estereoespecificidade do enantiômero mais ativo.

O desenvolvimento dos enantiômeros isolados levou muitas empresas produtoras de fármacos quirais a obter novas patentes para a produção e comercialização do composto puro (Tabela 2).

Tabela 2 - Exemplos de racematos que atualmente existem também na forma de enantiômeros puros.

\begin{tabular}{l|l|l}
\hline MISTURA RACÊMICA & ENANTIÔMERO PURO & NOME COMERCIAL \\
\hline Omeprazol (R + S-omeprazol) & Esomeprazol ((-)-(S)-omeprazol), & Nexium \\
\hline Citalopram (R + S-citalopram) & Escitalopram ((+)-(S)-citalopram) & Cipralex \\
\hline Albuterol (R + S-albuterol) & Levalbuterol $((-)-(\mathrm{R})$-albuterol) & Xopenex \\
\hline Ofloxacino ( R + S-ofloxacino) & Levofloxacino ((-)-(S)-ofloxacino) & Cravit \\
\hline Ibuprofeno (R + S-ibuprofeno) & Dexibuprofeno $((+)-(\mathrm{S})$-ibuprofeno) & Seractil \\
\hline
\end{tabular}

O estudo, desenvolvimento, produção e comercialização do um enantiômero puro de um racemato original é chamado de "chiral switching" e com essa prática várias empresas conseguiram estender o período de patente do fármaco. Essa estratégia vem se tornando um forte atrativo para o desenvolvimento de novos produtos, pois muitos estudos clínicos necessários para o desenvolvimento do enantiômero puro já foram realizados durante o desenvolvimento do racemato o que torna o processo mais dinâmico e barato. Somente em 2001 o mercado com fármacos enantioméricos puros foi superior a 147 bilhões de dólares (RAMACHANDRAN \& SINGLA, 2002).

A justificativa da concessão de novas patentes para o desenvolvimento e produção de enantiômeros puros é baseada nos fatos de que os mesmos apresentem uma ou mais das seguintes vantagens:

- $\quad$ maior índice terapêutico

- $\quad$ menor ou maior duração do tempo de ação (meia vida)

- menor variabilidade interindividual

- menor potencial de interações medicamentosas

- $\quad$ menor capacidade de desenvolver efeitos colaterais (Therapeutics Initiative, 2003).

Esperava-se que esses fatos levassem a uma maior segurança e eficácia no tratamento com o enantiômero puro que justifique, terapeuticamente e economicamente, o seu uso. Entretanto, muitos estudos 
desenvolvidos com enantiômeros puros que apontavam para alguma dessas vantagens não foram confirmados quando aplicados nem em estudos in vivo e menos ainda em testes clínicos (Therapeutics Initiative, 2003).

A talidomida, por exemplo, demonstrou, em estudos in vitro, a capacidade do enantiômero (R-) racemizar para a configuração (S-) o que significa que a utilização do enantiômero puro não evitaria, a princípio, o problema de teratogênese (KNOCHE \& BLASCHKE, 1994).

O desenvolvimento do antidepressivo (-)-(R)-fluoxetina foi abandonado por causa da mudança do regime de dosagem mais alta que o enantiômero puro trouxe ao tratamento (MCCONATHY E OWENNS, 2003).

$\mathrm{O}$ anti-hipertensivo labetalol também teve o desenvolvimento do seu enantiômero puro, dilevalol, cancelado em função da hepatotoxicidade causada pelo mesmo.

Um outro exemplo de que o racemato pode ser superior ao enantiômero puro é o caso do antidepressivo mitazapina (Rameron ${ }^{\circledR}$ ). A mirtazapina é um fármaco quiral comercializado na forma de racemato e pertencente a uma classe distinta dos antidepressivos tricíclicos clássicos por apresentar efeitos sobre os mecanismos de neurotransmissão noradrenérgica e serotoninérgica simultaneamente. Os enantiômeros da mirtazapina demonstraram diferenças farmacocinéticas e farmacodinâmicas significativas. A (+)-(S)-mirtazapina demonstra ter 10 vezes mais afinidade por receptores a2-pós-sinápticos e ser ca. 37 vezes mais potente para inibir autorreceptores a2 comparada a (-)-(R)-mirtazapina (DE BOER et al., 1995). Em contrapartida, a (-)-(R)mirtazapina é um inibidor do receptor 5-hidroxitriptamina cerca de 140 vezes mais potente. Justamente essas diferenças farmacodinâmicas dos enantiômeros da mirtazapina que confere a capacidade desse fármaco em aplicação nos casos de depressão. Desta forma é possível imaginar que a comercialização de um dos enantiômeros puro não teria o mesmo efeito do racemato.

Esses exemplos ilustram bem que enantiômeros puros podem ou não ser uma vantagem terapêutica em relação ao racemato, mas que a sua superioridade deve ser demonstrada na clínica para que o custo mais elevado do tratamento que os utilizam seja devidamente justificado.

\section{CONCLUSÕES}

No âmbito da comercialização e utilização de enantiômeros puros, assim como das reais vantagens apresentadas pelos mesmos, as informações que chegam aos profissionais da saúde devem ser claras e coerentes com os resultados dos estudos clínicos para que os mesmos possam, através de suas experiências profissionais, tirar suas próprias conclusões e adotar o medicamento que julguem mais eficiente para o respectivo caso.

A legislação brasileira vigente é pouco clara e de contribuição discreta para uma divulgação, estudo e controle adequado do assunto. Nota-se que o maior problema pertinente à compreensão e importância do assunto na saúde esta justamente nas classes farmacêuticas, médicas, odontológicas e veterinárias que correspondem justamente aos produtores, prescritores e dispensadores de medicamentos.

$\mathrm{Na}$ área acadêmica é preciso sempre enfatizar o assunto da quiralidade de fármacos em disciplinas de análise instrumental, controle de qualidade, química farmacêutica, farmacologia, bioquímica devem resgatar todos os aspectos relacionados ao assunto para que os profissionais formados transmitam esse conhecimento os diversos campos de atuação.

É preciso ainda que as corporações farmacêuticas que atuam no país saibam tratar, discutir e comercializar seus produtos com respaldo técnico-científico adequado.

No Brasil existe um número considerável de mestres, doutores e grupos de pesquisas que trabalharam ou trabalham com o tema da quiralidade. Esses pesquisadores e profissionais poderiam estar atuando de forma mais significativa caso o setor produtivo farmacêutico no Brasil desse a devida importância a esse tema.

A história do uso de fármacos enantiôméricos deixou claro que nenhum fármaco quiral está tão extensivamente estudado que tudo pode ser previsto sobre as diferenças farmacodinâmicas, farmacocinéticas e toxicológicas que seus enantiômeros irão apresentar. Portanto, estudos completos envolvendo a avaliação da eficácia, de efeitos tóxicos e a influência de diversos parâmetros como estados patológicos, idade, fatores genéticos, etc, devem ser muito bem avaliados antes da decisão final sobre a produção ou não do enantiômero puro. O mesmo vale para o controle de qualidade na produção e comercialização de fármacos enantioméricos racêmicos ou seus enantiômeros puros. 


\section{REFERÊNCIAS}

ANDREWS, P. Praziquantel: mechanism of anti-schistosomal activity. Pharmacology \& Therapeutics, v. 29, n.1, p.129-156, 1985.

BARREIRO, E. J.; FRAGA, C. A. M. Química Medicinal: as bases moleculares da ação dos fármacos. Rio de Janeiro: Artmed, 2001.

BARREIRO, E. J.; FERREIRA, V. F.; COSTA, P. R. R. Substâncias enantiomericamente puras (SEP): a questão dos fármacos quirais. Química Nova, v. 20, p. 647-656, 1997.

BERMUDEZ, J. A. Z.; BARRAGAT, P. Medicamentos Quirais: da dimensão química à discussão política. Cad. Saúde Públ., v. 12(1), p. 47-51, 1996.

CALDWELL, J. Stereochemical determinants of the nature and consequences of drugs metabolism. Journal of Chromatography, v. 694, p. 39-48, 1995.

COELHO, F. A. S. Fármacos e quiralidade. Cadernos Temáticos de Química, v. 3, p, 23-32, 2001.

De BOER, Th.; RUIGT, G.S.F; BERENDSEN, H.H.G. The IS-selective adrenoceptor antagonist Org 3770 (mirtazapine Remeron) enhances noradrenergic and serotonergic transmission. Human Psychopharmacology Clinical and Experimental, v. 10, p. 107-118, 1995.

ELIEL, E. L.; WILEN, S. H. Stereochmistry of organic compounds. 1 ed. Ed. Wiley Interscience.

FRANCOTTE, E. R. Enantioselective chromatography as a powerful alternative for the preparation of drug enantiomers. Journal of Chromatography A, v. 906, p. 379-397, 2001.

HYNECK, M.; DENT, J.; HOOK, J. B. Chirality: pharmacological action and drug development. In: BROWN, C. (Ed.) Chirality in drug design and synthesis. London: Academic Press, 1990.

KNOCHE, B.; BLASCHKE, G. Investigations on the in-vitro racemization of thalidomide by highperformance liquid-chromatography. Journal of Chromatography A, v. 666, p. 235-240, 1994.

KROEMER, H. K.; FROMM, M. F.; BÜHL, K.; TEREFE, H.; BLASCHKE, G.; EICHELBAUM, M. An enantiomer-enantiomer interaction of (S)- and (R)-propafenona modifies the effect of racemic drug therapy. Circulation, v. 89, p. 2396-2400, 1994.

KROEMER, H. K.; FUNCK-BRENTANO, C.; SILBERSTEIN, D; WOOD, A . J. J.; EICHELBAUM, M.; WOOSLEY, R. L.; RODEN, D.M. Stereoselective disposition and pharmacologic activity of propafenone enantiomers. Circulation, v. 79, n. 5, p. 1068-1076, 1989.

LIMA, V. R. E. Os fármacos e a quiralidade: uma breve abordagem. Química Nova, v. 20, p. 657-663, 1997. MAGOON, T.; OTA, K.; JAKUBOWSKI, J.; NEROZZI, M.; WERNER, T. C. The use of neutral cyclodextrins as additives in capillary electrophoresis for the separation and identification of propoxyphene enantiomers. Analytical and Bioanalytical Chemistry, v. 373, p. 628-631, 2002.

MARZO, A. How incoming guidelines on chiral drugs could impact on the international scenary of drug development. Bollettino Chimico Farmaceutico, v. 132, p. 267-271, 1993.

McCONATHY, J.; OWENS, M. J. Stereochemistry in Drug Action. Primary Care Companion, Journal of Clinical Psychiatry, v. 5, p. $70-73,2003$.

NOËL, F.; VOLPATO, N.; RIBEIRO, A.; EDILENE, B.; TATIANA, C. Estudo de bioequivalência para fármacos que apresentam estereoisomerismo. Revista Infarma, v. 16, p. 11-12, 2004.

RAMACHANDRA, U.; SINGLA, M. Surge in Chiral Technologies. Business Briefing: PharmaGenerics, p. 5054, 2002.

ROMERO, J. R. Fundamentos de estereoquímica dos compostos orgânicos. Ribeirão Preto, Ed. Holos, p. $15-24,1998$.

SANTOS, A. R. et al. Atropoisomerismo: o efeito da quiralidade axial em substâncias bioativas. Química Nova, v. 30 (1), p. 125-135, 2007.

SHINDO, H.; CALDWELL, J. Development of chiral drugs in Japan: na update on regulatory and industrial opinion. Chirality, v. 7, p. 349-352, 1995.

SOGLOWEK, S. M.; GEISSLINGER, G.; MOLLENHAUER, J.; BRUNE, K. Metabolic chiral inversion of 2arylpropionates in rat H4IIE and human Hep G2 hepatoma cells. Relationship to in vivo metabolism. Biochemical Pharmacology, v. 43, p. 1487-1492, 1992.

SOLOMONS, G.; FRYHLE, C. Organic chemistry. 7 ed. New York: Ed. John Wiley \& Sons, p.184-210, 2000.

THERAPEUTICS INITIATIVE. Do single stereoisomer drugs provide value?. Therapeutics letter [on line], Vancouver, junho-setembro, 2002. Disponível em: www.ti.ubc.ca/pages/letter45.htm. [capturado em: 31 ago. 2003]. 